South African freedom fighters who have taken refuge in Tanzania. A short-term visiting psychiatrist dealing with these groups above takes a considerable work load off the permanent staff. There is also the task of lecturing to the medical students, which takes about a third of the time.

Finally, the exposure to 'African' mental illness, together with the task of fitting it in to the ICD is a valuable training experience. Amazingly, the ICD is regularly used, perhaps because of the prevailing belief that the West has all the answers! It is with difficulty that this belief is dispelled, but it is possible, if the visiting doctor has the necessary humility, and accepts that the visit is a learning experience.
REFERENCES

INTER-UNIVERsITY CounCIL (1980) British Expatriates Supplementation Scheme. IUC/601/17/70. London: IUC.

(1978) IUC and Related Services: A Guide. Second Edition. Foreword by Chairman. London: IUC.

LEFF, J. (1977) The cross-cultural study of emotions. Culture, Medicine and Psychiatry, 1, 317-50.

Royal College of Psychiatrists (1980) Careers in psychiatry, p. 3. In Handbook for Inceptors and Trainees in Psychiatry, eds. T. H. Bewley and S. Mahapatra. Ashford, Kent: Headley Brothers.

Savage, A. (1979) Mission hospital medicine. British Medical Journal, ii, 111-13.

\title{
The Work of the Uffculme Clinic
}

\section{John A. Harrington, Consultant Psychiatrist and Medical Director, Uffculme Clinic}

The Uffculme Clinic opened 25 years ago as an early psychiatric treatment and research centre and has for the past 15 years functioned as a regional centre for psychotherapy in the West Midlands. Day and in-patients participate in a psychotherapeutic regime which includes a daily analytic psychotherapy group, relaxation therapy, projective art, psychodrama and more traditional occupational and recreational therapies. A weekly community meeting has recently been extended to give staff and patients a large group experience. Patients in intensive treatment are severely affected by neurotic or personality difficulties and are only admitted if they are incapable of functioning at work or at home.

At present there are over 20 out-patient evening or afternoon groups. Individual psychotherapy is offered to a small number of patients for whom group therapy seems inappropriate. There is a social club and a social skills group. Where behavioural therapy seems appropriate, patients are usually referred to the psychology department of their district psychiatric hospital.

\section{Registrar training}

Registrars undergo a year's intensive training in psychotherapy as part of a three and a half year rotational training scheme. Trainees can also attend a day release three-year MRCPsych course under the auspices of the University of Birmingham.

The registrar acts as therapist to an intensive group, supported by a nurse therapist. Each trainee is also therapist to an out-patient group and undertakes individual psychotherapy with a small number of specially selected outpatients. He also sees new out-patients for assessment and participates in brief and supportive psychotherapies and conjoint marital work. Each trainee has a weekly session with a consultant superviser, and there is also weekly group supervision with a consultant psychotherapist. Trainees all participate in a conference when all newly admitted patients are seen. Other training activities include a journal club and weekly staff meetings.

The rotation to Uffculme is best carried out in the last year of a registrar's rotation; trainees seem to gain more from psychotherapy if they are familiar with an eclectic approach to psychiatry. Fifteen years ago, when the scheme first started, Uffculme was not always popular; some trainees saw psychotherapy as alien or irrelevant to the practice of psychiatry. Nowadays most trainees are keen to have psychotherapeutic experience and may continue their links with the Clinic by continuing with their out-patient groups and one or two individual patients.

\section{Higher paychiatric training}

Higher psychiatric training for senior registrars takes the form of either one or two years' full-time experience in Uffculme as part of a rotational scheme, and generally after spending two years in another unit.

A substantial number of the scheme's 20 senior registrars have an interest in psychotherapy. Preference is given to trainees who have not been at Uffculme as registrars and to those who express a wish to train for a consultant post in which they will have opportunities for a special interest in psychotherapy. As such consultant posts are limited, most senior registrars keep their higher psychiatric training broadly based lest they should restrict future job opportunities.

Senior registrars unable or unwilling to attend Uffculme full-time are encouraged to take part in a two-year multidisciplinary course in psychotherapy. This takes half a day a week. The first year includes seminars on basic psychotherapeutic concepts and techniques, and a sensitivity training group. The second year involves a more intensive personal group experience. A personal analytic experience is not regarded as essential, but trainees who see this as impor- 
tant are allowed time off for personal therapy at their own expense.

\section{Psychotherapy training for nurses}

The Uffculme Clinic was chosen as the first centre to run a Joint Board of Clinical Nursing Studies' course on psychotherapy. The first group of six nurses has just completed the course with gratifying results. These nurses co-lead intensive and out-patients groups; they also receive training in other therapies. The nurses take part in a weekly group experience with a group analyst and attend a day release course for psychodynamic training. It is encouraging to see the high calibre of applicants for such courses and trainees have been notably enthusiastic about their psychotherapeutic role.

\section{The West Midlands Institute of Psychotherapy}

This charitable institution has just been established and is based at Uffculme. It was brought into being with assistance from the Regional Health Authority in order to fulfil a regional need to bring together mental health professionals, including doctors, psychologists, social workers and marriage guidance counsellors, who have a special interest in psychotherapy or counselling. The Institute has over a hundred members, and, apart from monthly meetings, plans are being laid to develop further training courses.

\section{The Regional Centre for Postgraduate Psychiatry}

This is based at Uffculme and run in close conjunction with the Board of Graduate Clinical Studies of the University of Birmingham. It is responsible for the organization and administration of the schemes for higher psychiatric training, including the sub-specialties. Apart from the schemes and courses already mentioned, it organizes regular courses in family therapy and a training course in child development and analysis in conjunction with the Tavistock Clinic. It acts as a focal centre for the distribution of information about forthcoming meetings and training courses of psychiatric interest.

\section{Undergraduate Teaching in Psychiatry}

\section{Greg WiLkInson, Joint Senior Registrar, King's College and Maudsley Hospitals}

A workshop on the teaching of psychiatry to undergraduate medical students was held at the Institute of Psychiatry on 6 May 1981. Dr S. Greer and Dr C. Bass organized the meeting on behalf of the Association of University Teachers of Psychiatry, and there were sessions on four topics during the day; recruitment to psychiatry; the measurement of students' attitudes towards psychiatry and the use of 'liaison' psychiatry as a teaching method; the use of videotapes in teaching medical students interviewing skills-a practical demonstration; and a panel discussion of the problems in teaching undergraduates psychiatry.

Professor Gerald Russell (Institute of Psychiatry) began by asking the question 'How can recruitment to psychiatry be improved?' Evidence from the UK and the US fails, in general, to support the notion that improvements in undergraduate psychiatric education lead to an increased recruitment of psychiatrists. Instead, recent opinion suggests that the number of entrants to psychiatry is determined by ideological changes in society and economic and financial considerations. DR PETER BROOK (Fulbourn Hospital). spoke about the role of the medical schools in influencing career choice. Some schools consistently produce more psychiatrists than do others. Between 1966 and 1975 almost 7 per cent of University College Hospital graduates went into psychiatry, whereas only about 2 per cent of the London Hospital students did so. Schools at the 'top' of the 'league' have a relatively higher ratio of teaching consultants; and on average their students have a week longer psychiatric clerkship than do those whose schools were in the 'relegation zone'. Charismatic teachers seem to attract students to a career in psychiatry. Although neither speaker was able to give a clear explanation for the apparent decline in recruitment, two intriguing suggestions were raised for discussion. If the financial hypothesis is correct, then doubling the salary for mental handicap posts should increase recruitment to that sub-specialty (DHSS please note). Also, the College might like to consider ways of comparing standards of undergraduate psychiatric education in medical schools, and then through the use of student 'case-registers' graduates might be followed up to shed light upon the determinants of career choice.

Next, Charlotte Feinmann (King's College Hospital) presented the results of a questionnaire study designed to assess the effects of an eight-week course of instruction to improve clinical students' general interviewing skills. The questionnaires self-rated the students' attitudes toward, and competence at, interviewing; but there was little change in either despite the instruction. This might have reflected an increased sense of self-criticism in the participants. An incidental finding was that most of the subjects were enthusiastic about teaching received on ward-rounds and in out-patients rather than in other settings. DRS GREER and WILkINSON (King's College Hospital) described the preliminary results of a longitudinal study of medical students' attitudes towards psychiatry. Most of the King's students, happily, end their clerkship with a more enlightened view about psychiatric practice than when they start, but a few develop negative ideas about psychiatry. This second session of the day was completed by DR C. BASs (King's College Hospital) who gave a persuasive account of the potential role 